\title{
Methods in Population Forecasts
}

\section{Methods in Population Forecasts in Denmark}

The Present System and Planned Improvements

By S $\varnothing$ REN HOSTRUP-PEDERSEN

Central Statistical Office of Denmark Copenhagen

The most recent official population forecast in Denmark was calculated by the Danish Statistical Office in 1963. The population forecast was made on a countrywide basis, and related to the calculated number of people at the beginning of each of the years 1963-80. The calculation technique was used for births in one-year fertility quotients from the calendar year 1961, while the mortality was based upon figures obtained from the two-year period $1960-61$. With a view to migration between Denmark and abroad, a choice was made in the projection that a net migration of 0 would be taken into account for all age classes, and for men and women.

\section{Fertility}

The reason for the use of fertility quotients from 1961 in the forecast was that the shift in fertility from the older to the younger women's age classes stagnated in the years up to 1961 .

Only the collected figures for the whole country were taken into consideration, and no note was taken of the geographical fertility differences which have in fact now been established. Accordingly, it was decided to ignore the effect exerted upon fertility by internal migration. Moreover, by reason of the weak statistical material, it was decided to ignore the time of entering into marriage, and the duration of marriage. Changes in the distribution of permanence in marriage occur at a very slow tempo, and a forecast should not be regarded as having validity for a long period of time. Nowadays, changes in the community take place at such a speed that one can not in any way calculate that the assumptions for forecasting have any great chances of showing themselves as obtaining for long 
periods at a time. However, if forecasts valid until 1980 are made, some forecasts extending as far forward are dependent upon the application in community planning of information on the future population for different times in the future. Nevertheless, one should be careful to observe that the "forecast" can be no more than a projection of the magnitude of the future population in the future, under rather decided assumptions. Consequently, the projection tends to be only the best current opinion which can replace pure guesswork.

Another thing which it has been necessary to ignore is the distribution of live-borns in the number of births. In the Danish population statistics, no knowledge is available of the distribution of nativity. In Denmark, one has only information on the number of live births divided up according to the number of pregnancies of the mother, abortions included. As it is impossible to acquire any clear picture of the number of abortions reported by midwives at birth, accordingly it is impossible also to get any certain perception of the distribution of the number of children in the birth statistics. Hereby, one is cut off from information on the size of families, and is consequently not in a position to present a definite opinion on the changes that have occurred with respect to the distribution of families with one, two, three or more children.

\section{Mortality}

In the years before the most recent population forecast, there was discernible a weak tendency towards a fall in mortality that characterised the past years of the twentieth century. As far as men were concerned, the mortality evinced a weak rising tendency while the mortality of women fell very slowly.

In particular, the mortality of men between the ages of 50 and 70 showed a rise. At that time, it was difficult to see whether it was a matter of a transient phenomenon, or a lasting state of affairs. In fact, one is in the same position today, as the results for the year 1967 have just become available, and these once again show a decline in mortality, with the years from 1961 to 1967 evincing a weak rise in men's mortality, and an unchanged mortality for women.

As a result, it was decided that in the 1963 forecast unchanged mortality quotients would be used.

\section{Internal migrations}

The forecast was a total one, and it was decided that the internal migrations would be left out of consideration. The statistical material that 
was available on the influence exercised by migrations on the other factors was very weak in nature. Subsequent investigations have shown that migrations affect the magnitude of fertility, in that immigrants slowly take up the pattern of life applicable in the area concerned. As the individual changes in fertility play a continuous role, the internal migrations mentioned can influence the number of births to a not unimportant degree. In a regional forecast, just published, from the "Secretariat of the Land planning Committee", the influence of internal migrations has been included in the collective number of births.

\section{Migration abroad}

In view of the experience gained in 1961 with respect to emigrations from Denmark to foreign countries, and in view of the order of magnitude of migration abroad, the opinion was held that no heed should be paid to emigrations from Denmark. Definitively, the foreign migrations are to a greater extent than the other motive components dependent upon the political and economic situation in both Denmark and abroad.

\section{Revision of the forecast}

As it will soon be five years since the last forecast was made public a revision is now due, with note taken of the changes that have taken place in regard to the different components concerned. The preparations for the new forecast have been more fundamental than before. We have initiated a long series of investigations of the bases of components, and the geographical differences that exist. In regard to fertility, investigations have been published on the differences in geographic fertility for births both in and outside wedlock. As regards mortality, there has been published "Recent tendencies in mortality», which provides a more detailed analysis of the rise in mortality mentioned, divided up into groups concerned with age and reasons for death. Infant mortality has also been the objective of a more detailed investigation, published in »Infant mortality in Denmark, 1931-60». Furthermore, there is in preparation a publication on geographical differences in mortality and another on cohort fertility.

In addition to the above, we have embarked upon fundamental analyses of the deviations that have appeared between the calculated age distribution and the forecast. The result of this compilation has, for the years until January 1 1967, given the result that there exists close agreement between the calculated age distribution and the forecast for the age classes born at the time of formulating the forecast, but the number 
of births after the time of forecast has proved to be somewhat larger than that forecast, partly by reason of a slight rise in the total nativity, and partly as a consequence of a continuous shift towards lower women's ages, which are in number somewhat larger than the slightly older age classes.

Taken things as a whole, accordingly, it can be said that the preparations undertaken on this occasion are more basic than was the case earlier, and that as a result we are prepared to begin work on revision of the forecast.

Fortunately, we did not manage to formulate a forecast before the surprising information concerned with 1967. The number of births was about 12 per cent below the figures expected, and was significantly more at the end the year than at the beginning. At the same time, mortality showed a decline which was by no means slight. The available figures in regard to the first quarter of 1968 show the same tendency as the fourth quarter of 1967 , in that there was a fall in the total nativity of about 20 per cent in comparison with 1966, if the remainder of 1968 shows the same magnitude as the past part. The reason for the decline in nativity may well be attributed to liberation of the antipregnancy pill from October 1 1966. The decline started weakly early in 1967 , but conceivably is connected with easier access to the pill during the time of the liberation.

It is difficult to state with any certainty what effect the opportunities available for birth control will have upon future fertility, of course. Although a general decline seems indicated, the possibilities of self-planning may result in a desire for more children, when one can exert a greater infuence upon the division by time of births than has hitherto been the case.

Nevertheless, it is quite clear that there cannot be expected a revised population forecast from the Danish Statistical Office before we know which women use the pill, with a foundation of distribution by age, duration of marriage. geographical and social distribution, and so on. 